Article

\title{
Who 'Uses' Smart Grids? The Evolving Nature of User Representations in Layered Infrastructures
}

\author{
Antti Silvast ${ }^{1, *}$, Robin Williams ${ }^{2}$, Sampsa Hyysalo ${ }^{3}$, Kjetil Rommetveit ${ }^{4}$ and Charles Raab ${ }^{5}$ \\ 1 Department of Anthropology, Durham University, Durham DH1 3LE, UK \\ 2 Science, Technology and Innovation Studies, University of Edinburgh, Edinburgh EH1 1LZ, UK; \\ robin.williams@ed.ac.uk \\ 3 Aalto School of Art, Design and Architecture, Aalto University, FI-00076 AALTO Espoo, Finland; \\ sampsa.hyysalo@aalto.fi \\ 4 Centre for the Study of the Sciences and the Humanities, University of Bergen, 5007 Bergen, Norway; \\ kjetil.rommetveit@uib.no \\ 5 Politics and International Relations, University of Edinburgh, Edinburgh EH8 9LN, UK; c.d.raab@ed.ac.uk \\ * Correspondence: antti.e.silvast@durham.ac.uk
}

Received: 29 August 2018; Accepted: 12 October 2018; Published: 17 October 2018

\begin{abstract}
This article addresses the anticipated use and users of smart energy technologies and the contribution of these technologies to energy sustainability. It focuses on smart grids and smart energy meters. Qualitative accounts given by European technology developers and experts reveal how they understand the final use and social impacts of these technologies. The article analyzes these accounts and compares the UK's smart meter rollout with experiences from other European countries, especially Finland, to provide insights into the later adoption stages of smart energy and how its impacts have evolved. The analysis highlights significant differences in the likely intensity and manner of user engagement with smart grids and meters: depending first on whether we are considering existing technologies or smart technologies that are expected to mature sometime in the next decade, and second on whether the 'user' is the user of smart meters or the user of an entire layer of new energy services and applications. By deploying the strategic approach developed in the article, smart grid developers and experts can give more explicit attention to recognizing the descriptions of 'users' in smart-grid projects and to the feasibility of these expectations of 'use' in comparison to the possibilities and limits of energy services and applications in different country contexts. The examination of user representations can also point out the need for further technology and service development if some of the envisioned user profiles and user actions appear unrealistic for presently available technologies.
\end{abstract}

Keywords: expectations; infrastructure; Science and Technology Studies; smart grid; smart meters; sociology of user representations.

\section{Introduction}

This article explores smart technologies, focusing on smart grids-electricity infrastructures that involve the increasing use of information and communication technologies (ICTs) - and smart-energy meters-among the prominent components of smart grids, installed in domestic buildings, businesses, and other sites of energy usage to enable two-way communication between energy suppliers and consumers. We utilize insights from two related social science literatures to examine these technologies and their social impacts. First, we draw upon the sociology of user representations to explore how the designs of smart technologies 'embed' specific assumptions about their users: for example, regarding who they are expected to be, what uses these technologies would have, and what the situations of 
use will be like. It is important to scrutinize the way in which developers' and promoters' discourses about 'smartness' shape the ways in which technologies are conceived, implemented, and used. As an infrastructural technology, the smart grid involves various actors at different levels, from energy suppliers to energy service companies, automation analysis software providers, consumers who generate their own energy, and several others. We are particularly interested to explore the different conceptions of 'the user' and representations of use across these several layers. Further, the article shows that representations of users in layered smart grid infrastructures vary not only across space but also across time. Users and uses are not constructed once and for all by actors, but evolve across cycles of development and use, shaped by the evolution of energy systems and services in smart energy infrastructures.

Second, the sociology of expectations allows us to place the representations of users alongside broader infrastructural visions-such as energy decarbonization or cost minimization. Expectations are real-time representations of future technological capabilities, and the key concept of expectation work designates those activities-such as pilot projects, simulation models, qualitative scenarios, and cost-benefit calculations-that experts use to bring the expectations about. Once aligned with these kinds of vision, representations of users in smart technologies may become embedded in whole industrial fields. Such user-related expectations have strong potential impacts in coordinating activities and aligning the interests of actors, for example in energy market regulation, standardization, and investment. Hence, they merit the kind of detailed analysis that we develop in the article.

Over the past decade, smart grids have been the focus of major energy investment and infrastructure modernization policy programmes all over the world [1-4]. Energy suppliers and distributors are expected to enjoy major benefits from smart grids and meters through improved energy peak-load shifting, emissions reduction [5], smaller meter-reading costs, and reduced operational expenses [6]. Proposals for 'smarter' energy systems sit alongside a great number of other 'smart' development projects and initiatives-from 'smart' cities to 'smart' health-conceived as ways of resolving an increasing range of issues including the impacts of climate change, citizen participation, the ageing population, and ensuring economic growth. These ambitions are evident at the European Union (EU) level and in industrial and developing states, and among various industrial sectors, policy-makers, researchers, and expert circles $[7,8]$.

The needs and contributions of the energy 'end user', 'final user', 'consumer', 'customer' (or other related terms) figure prominently in 'smart' energy programmes. In EU policy documents, deploying smart grids and metering promises new possibilities for self-managing energy consumption, improved energy efficiency among final consumers, and transition to more consumer-centric energy systems $[2,9,10]$. Additionally, the United Kingdom's (UK) smart metering programme, the focal point of our present inquiry, has emphasized consumer protection and consumer engagement with the new smart meters [11]. Recently, it has focused on how households and small businesses might be given 'incentives' to accept smart meters voluntarily, such as accurate automatic billing, cost savings, and real-time energy consumption feedback $[5,12,13]$.

Meanwhile, in some countries, people have reacted to and opposed smart-energy meters because of concerns over the protection of their personal data, to avoid information overload, or particularly in the United States (US), health [14]. The Netherlands, the US, the UK, and Canada have seen either anti-smart meter campaigns, lawsuits against smart metering, critical reports by consumer organizations, or motions passed by governments [15]. Events like these relate to the supposed 'users' of smart grid technology in various ways. These range from rejecting 'use' because of intrusion on the right to privacy in the Netherlands $[16,17]$ to the emergence of networks of counter-experts and democratic contestation, paving the way to health-oriented precautionary politics in California [14].

In this article, we examine these various representations of smart grid users. We pay close attention to the nature of representations of users in smart energy development projects, their likely evolution, and hence the mechanisms by which these projections of future use may eventually affect people's lives. The article develops Science and Technology Studies (STS) perspectives to address this situation. 
More specifically, it examines how STS research on user representations may help to understand the anticipated use and users of smarter energy technologies. By studying these uses and users, we also produce a more subtle understanding of how exactly smart energy technologies might contribute to sustainability in energy systems. To these aims, we draw upon and advance a considerable body of STS research on user-technology relationships $[18,19]$ and the technological, social, and policy assumptions and implications of smart grids and meters [20-30]. The article addresses two overarching research questions:

1. What kind of user-related expectation work is carried out in smart grid projects?

2. What do these representations of users and user-related expectations reveal about the evolving social impacts of infrastructural technologies such as smart grids?

We elaborate our approach drawing on findings from the EU Checking Assumptions and Promoting Responsibility in Smart Development Projects (CANDID) research project. This project explored, inter alia, how European technology developers and experts understand the final use and social impacts of smart grids and smart energy meters. Inspired by an interest in user representation in smart grid projects, our analysis of this data focuses on various ways in which smart grid development experts structure their view of users. While data collection was constrained by the short (12 month) duration of our study, we use cross-country comparison as a 'proxy' for studying the evolution of user representations in smart grids over time. The UK's smart meter programme will be considered as being in an early adoption stage, while experiences from other European countries-Finland in particular-help us to gather insights into the later adoption stages of smart energy and the evolution of its impacts.

This analysis contributes theoretically to the sociology of user representations in complex and long-term infrastructural projects and recapitulates earlier findings on user representation. These showed that there is a range of competing user representations regarding an emerging technology; that the diversity of users and situations of use is reduced to manageable development visions through simplifying user characterizations; and that these representations play roles in the expectation work involved in the development of emerging technologies. Our results also offer the possibility to develop these conceptual tools. In particular, smart-grid user representations draw attention to important new issues in the representation of users in multi-layered infrastructures. There exist vast differences in the likely form and intensity of user engagement with smart grids and meters; differences in whether the representations refer to current smart technologies and uses or to developments that are expected to emerge and become established over the next ten years; and in whether the user is envisaged as the user of smart meters or of an entire layer of new energy services and applications.

The structure of the article is as follows. The first section explains our conceptual position on smart energy technologies, starting from the sociology of user-technology relationships, user representations, and expectations and reviewing initial social science and humanities scholarship on smart energy. It then introduces the CANDID empirical study, presenting it by focusing on key aspects of how 'users' become represented in expectation work-to be explained in Section 2-related to smart grids, smart metering, new energy-saving and load-shifting services, and promises of new kinds of energy consumption and self-production —or 'prosumption' - at the household level. Finally, the conclusion draws out more general implications for understanding user representations and suggests possibilities for further work in research and development of smart grids from the perspective developed in this paper.

\section{Literature Review}

\subsection{Who Are the 'Users'? User-Technology Relationships and the Sociology of User Representations}

The high hopes and fears related to smart metering and smart-grid projects may obstruct a more realistic understanding of how these technologies will be applied and their consequences for various stakeholders. Ideas of 'smartness' and its supposed beneficiaries invite us to consider more carefully 
how 'users' — whoever they are — and their 'needs' — whatever they are — may be met by smart-grid projects. STS scholarship has focused on user-technology relationships for several decades [18,19,31-35] and provides a very promising vantage point for exploring this. STS work on 'users' opens up several questions about who or what the 'users' of technology are expected to be; how representations of 'users' feature in developing expectations that mobilize resources and shape the trajectory of future developments; how designers represent and relate to these 'users' and how they understand their characteristics; and how 'users' may use technologies in a different manner than designers envisaged and in so-doing may re-shape the design.

Considering the meaning of the term 'user', a key contribution of this STS research has been in showing that in empirical sites of technology production the 'user' is not merely considered as an identifiable person, but as a conceptual entity relational to the developers of technology $[33,36]$. This relationality means that researchers and developers tend to represent eventual users during technology design by extrapolating from business models, market studies, consumer panels, co-design workshops, or even just common sense, in the hope that these will 'bridge' towards these users [35]. These user representations link multiple modalities of emerging technologies: visions, requirement specifications, models and prototypes, marketing materials and manuals, pilot assemblies, and eventually uses by concrete people in concrete settings [37].

The sociology of user representations [36] examines the processes that lead to particular actor positions becoming embedded or 'scripted' into the characteristics of technology [38]. These characteristics concern who the users are, what they are supposed to do with that particular technology, and in what situations. This sociology examines how configurations of users come into being and how they may become accepted, altered, or rejected by eventual adopters [32,39]. Initial concepts characterizing these relationships-such as the concept of 'script' in technology or Woolgar's [38] suggestion that designers seek to 'configure the user'-targeted relatively discrete and clearly delineated objects, such as solar batteries, computer hardware, or even door closers [32,38]. These mostly featured 'closed'-i.e., limited and singular-scripts for specific actions rather than 'open' scripts and 'circumscriptions' that would cater for an unspecified but wide array of possible user actions $[40,41]$.

When considering more complex technologies the notion of a closed script was not sophisticated enough. In such technologies, designers' 'configuration of the user' was rather like a preconfiguration [42]: an expression of how designers might prefer the users to be acting with the technology. Yet, such idealizations were confronted by and merged with various other preconfigurations in users' settingsfrom procedures to habits, norms, conventions, and beyond-leading to various 'reconfigurations'. Moreover, when it came to the influence of 'smart' interactive information technologies on users, the configuration process did not play out as a simple one-time contestation but tended to evolve across cycles of development and use, and also to evolve in conjunction with the development of adjoining systems and services [37,39,42,43].

This newer understanding of developer-user relations has been paired with more sophisticated understandings of user representations. One important source of understandings arises from the efforts of designers and developers to develop more effective representations to inform their design and development work $[33,37,43]$. There is considerable variation as to how specific and detailed the representations are: some are based on clearly delineated user demographics and specific use cases and are typically found in specific application contexts or as clearly targeted parts of larger systems [35,43]. However, in mass-produced consumer goods and services and large systems, the diversity among users increases beyond what can be meaningfully responded to by means of segmentation, need analysis, or product differentiation. A common developer response has been to respond by imputing no longer specific users but simply actions that users would perform with the technology, en-masse [33,43].

Furthermore, STS research on information infrastructure $[44,45]$ has shown that the diversity of potential future users and uses often overwhelms its developers. The risk is that they will roll out what are already (or will soon become) legacy systems. To this end, those involved in building 
such information systems have adopted more experimental development strategies that continuously monitor, configure and manage their 'communities' of 'users' [34,46,47].

However, these user representations are not held only by design teams, and not all end up as features in products. Some user representations circulate among particular companies but may never result in design features [42], and yet others concern whole technology fields [39,48,49]. Konrad [49], for instance, observes how representations of users and the ensuing 'scenarios of use' for Interactive TV remained remarkably stable for over a decade around the turn of the millennium, despite considerable technological advances and the surrounding development of Internet technology. Meanwhile, the evolution in e-commerce scenarios of use was so rapid that the producer companies did not even have time to test their adequacy in real-life applications in their race to adapt and shape the visions that drove the overall development of this business field. In such field-shaping efforts, wide arrays of user representations can be purposively cast to have a mobilizing effect on a range of actors in industry and policy $[39,49,50]$.

Williams et al. [39] and Stewart and Hyysalo [51] observed information technology development further, outlining various kinds of layering in these contexts, including horizontal and vertical layering of technologies as well as users, and creating correspondingly layered user representations. First, ICT technologies featured intermediary service providers who assembled component technologies into product and service offerings; intermediate users such as work organizations and bespoke service providers that configured systems for final users; and proxy users who informed the development. Second, the technologies featured several layers: an infrastructural hardware layer of routers, servers, electricity networks, and beyond; a software infrastructure consisting of, for example, Internet protocols, low-level computer software, and operating systems; and various application software that 'end users' would mostly be using rather than the infrastructures working 'invisibly' at another layer. All these layers would have completely or somewhat different user bases and consequently different representations of their use.

Similarly, unpacking smart grids reveals a large cast of characters. This includes energy suppliers, electricity distribution operators, 'next-generation intermediaries', automation analysis software providers, price-comparison websites, energy regulatory agencies, and marketing and promotional actors, and several others are coupled to the promises of smart grid. These promises are shaped by broader infrastructural visions, such as decarbonization and cost minimization. Smart meters are also meant to operate along with other 'smart' home technologies, interacting with everyday objects and the Internet of Things, thereby paving the way for standardization, new markets, and business models.

Such visions and field-wide arrays of user representations are part of expectation work that is important in coordinating actors and aligning interests, convincing investors, achieving standardization, and developing regulation. This topic has been addressed within STS work on the sociology of expectations $[49,50,52]$. Expectations refer to "real-time representations of future technological situations and capabilities" and "wishful enactments of a desired future" [52] (p. 286). By guiding activities, expectations are fundamentally generative or 'performative': they not only describe desired future technological and economic situations, but may also partially bring them about, at least for a time [53]. Expectation work refers to the activity-ranging from roadmaps and qualitative scenarios to cost-benefit analyses, pilot projects, and simulation models- that produces these representations of futures in practice.

These insights into the representation of the 'user' and expectation work are also directly relevant in thinking about large energy systems and infrastructures [54,55]. In fact, the literature on user representation has been actively employed in making sense of the evolving smart-metering and smart-grid systems.

\subsection{Social Science and Humanities Research on Smartness and Smart Grids}

In earlier social science and humanities research, an important context of smart grids and smart meters has been seen as the wider drive to make many aspects of our societies 'smart'. This 'smartness' 
is defined by a certain kind of modernism, meaning increased rationalization and individuality. In these accounts smart grids, their 'users', and uses often relate to, for example, projects of smart urbanism, resilience and self-healing of energy systems, integration of smart grids with smart home technologies, integration of digital and non-digital infrastructure, and data sharing among various actors. Studies indicate that smart energy constitutes an entire 'smart' ontology that constructs new data-driven relationships between energy producers and users [23]. Smart grids are expected to enable more intelligent management of electricity networks, especially to cope with intermittent renewable energy sources such as wind and solar [56]. Smart grid and smart meters are key in wider transitions to 'smart' urbanism $[57,58]$. At the level of households, smart meters also promise to be central in enabling information flows in the 'smart' home $[59,60]$.

Ballo [25] (p. 12) applies the concept of socio-technical imaginaries in order to "explore how actors produce future visions or imaginaries that describe desirable or and feasible futures" in smart grid projects. The Norwegian smart grid initiatives that she studied mainly draw upon two separate 'visions' that she labels technological (e.g., adding electricity grids with intelligence, utilizing new data) and economical (e.g., combining electricity grids with a market logic, creating new possibilities of action for energy consumers) that are also nationally bounded. Similarly, a study in Washington State found distinct meanings of the smart meter concept among utilities, academic research and development laboratories, regulators, and technology firms. On different occasions, the smart meter was conceptualized as a tool for economic efficiency, as a democratization project, or as part of a vision of a new machine-governed society, while the necessity of interoperability among the components of the future's smart grid was also flagged [4]. Other works have used the concept of imaginaries to explore how smart grids also produce visions of very different smart grid 'users' [28]. One key expectation has been that individuals' behavioural changes will be triggered by smart technologies such as smart meters, driven by energy and cost savings [23,61].

Similar 'preconfiguration' of certain kinds of user in smart-energy industry standards and energy policies has also received attention [21,62,63]. Throndsen [28], reviewing literature on smart grid research papers, argues that preconfigurations of the residential smart-grid user fall within three wide categories: economic configuration (making 'users' more active in an economically rational way); technical configuration (automation of energy consumption and bypassing active forms of use); and social science configuration (comparing visions of imagined users to 'real' users, whoever they may be). Coming to very similar conclusions, a study of Danish smart grid experimentation projects discovered three main 'scripts' that inform the interaction that these projects expect between household consumers and future smart grids: an economic incentives script, an automation script, and an information and visualization script [64]. At the same time, many social science scholars of smart grids and smart meters have reacted to these types of preconfiguration of the user and their models of rationality by highlighting the diverse and often unpredictable ways in which consumers engage with smart energy, most typically in their homes $[22,27,65-67]$ but also partially as part of wider settings such as residential areas [26].

These are valuable insights especially for understanding why supposed 'users' may wish to become 'non-participants' in the smart grid, for example in smart-grid demonstration sites [62] or by being not involved in smarter energy services [66]. Yet, these examples and literature call for a more dynamic way of characterizing the relationship between producers and users in smart-grid projects, and more extensive engagement with the sociology of user representations and its importance for the development of complex new infrastructural projects that we have outlined in Section 2. To this end, we build on empirical work on the representation of users and uses in smart grids and smart metering to develop a theoretical contribution to this debate. We advance a new, more dynamic position on user-technology relationships by focusing on the diversity of representations of 'user' in smart grid projects, and by highlighting the kind of attention given to 'final users' and use among expert participants and project developers. The research methodology for addressing these dynamics 
needs to pay close attention to who is an 'expert', what they know about the 'final users', and how they know them in these projects, as we show next.

\section{Materials and Methods}

The remainder of this article explores the findings from the CANDID project in which the views of smart-grid and smart-energy 'experts' were gathered in order to cast light on the issues discussed above. Our research design was inspired by the method of an 'extended peer review', developed notably by Funtowicz and Ravetz [68]. At the core, the extended review method aims at broadening the selection of individuals and groups whose knowledge and experience are consulted to more fully understand research outputs, such as 'smart grids for sustainable energy use' [8]. An extended review gathers feedback and comments on a specific problem from practitioners across various groups, including those developing scientific research (normally colleagues or other immediate 'peers') and those designing, profiting from, evaluating, sharing, or encountering the products of science in their everyday work or lives.

To accomplish this, we developed a consultation form that contained an extended explanation of the research project followed by ten open-ended questions. Operationalized within the CANDID research group by applying insights from the sociology of user representations and expectations literature, the questions focused on different kinds of user of smart energy; their capabilities and constraints in adopting smart energy technologies; how the design process of smart energy technology takes users into account; protection of their privacy; and possible national variations in smart energy, especially in the EU (see Appendix A for the full structure of the questions).

A pool of 71 subjects was selected to encompass a range of respondents, academics and nonacademics as well as engineers and social science and humanities researchers. Our research drew on social scientific interview and survey research techniques but built upon these to go beyond the conventional single-site qualitative study. We wanted to involve social science and humanities scholars as well as engineers in our consultation and also include those advising people on smart meters, information campaigners, and the electricity industries, among many others. While we could reach only a subset of these groups in our sample-with researchers over-represented-the extended review method still importantly guided us to look for insight on smart energy from the views of experts at many relevant layers of the smart grid infrastructure. This aim was fulfilled sufficiently to further this understanding, this vindicating the application of the method.

The project received 21 responses, giving a response rate of 30 percent. All the responses have been anonymized. The subjects were asked for their consent for inclusion before they participated in the study. This protocol was approved by an ethics consultant who was part of the CANDID project. Sixteen respondents were academic researchers on smart technology. The whole dataset has a mix of engineering experts (12) and those representing social science and humanities (9). Outside universities, the experts studied (5) worked for associations (e.g., energy conservation, smart energy campaigns, citizens' advice) and a consultancy. Men were overrepresented (13 men, as compared with 8 women). Most of the experts were based in the UK (15), which was our main focus, but the materials also contain responses from Finland (2), Austria (2), Italy (1), and Australia (1). To gain further feedback from this extended group of 'peers', selected respondents participated in the research project's one-day workshop, where we introduced our preliminary findings and elaborated them further in a roundtable discussion. We draw upon both the results of the consultation and the results from the workshop discussion, complemented by case examples from European countries, documented elsewhere $[17,27,66,67,69,70]$.

Our interest in the evolving nature of user representations led us to adopt a particular methodological strategy for data analysis. In the sociology of expectations, extrapolating visions from the current moment is not always particularly helpful per se. Stronger insights arise from tracing the evolution of promises-regarding how they have changed over time, or between various sites of technology such as production and consumption $[39,71,72]$. The CANDID data, which mainly stems from expert 
engagements over one year, does not directly allow a longitudinal perspective. Therefore, as an alternative, we used cross-country comparison as a 'proxy' for inquiring into the early and more mature stage of adoption of smart energy technologies. In particular, as mentioned earlier, the UK-from which most of our data originates-is considered to be in an early adoption stage. Other European countries, Finland in particular, was used to derive insights into the later adoption stages of smart energy, based upon the country's full rollout of smart meters and the new layers of energy services that have emerged because of this.

\section{Results}

\subsection{Layered Infrastructure and Layered 'Use': Smart Meter Users or Users of Smart Electricity Services?}

In current policy programmes, marketing campaigns, and some development projects, smart meter users have become very central loci of intervention and discussion. Policy pronouncements and promotional materials on smart meter rollouts frequently emphasize that smart grid and smart metering will allow end-users to monitor their energy use and thereby potentially save money. This is expected to apply in (or is at least promoted in relation to) ordinary households. The informants in our study typically referred to these behavioural visions as their starting point. As a representative of a publicity campaign for smart meters expressed it:

Smartness has two components: enabling responsive consumers and near real-time information.

It allows you to change your behaviour. It allows you to do things that you couldn't do before by responding to data, such as refurbish your home's heating systems you could not do in the same way by using the 'dumb' meter.

Two academic researchers who responded also exemplified this premise of putting rational individuals at the centre of 'smartness'. One of them thought that "people say they want information that they can use, so if they know that they're spending a relatively large amount of money on say taking really long showers, then they know they can do something about it." Another concluded similarly: "You could say I'm going to have an intelligent battery that just charges when it's cheap and then I'm going to spend the electricity later. Then you can think of very smart things."

A response from Finland differs from these expectations in some respects, though it also shares the key premises on 'smartness' benefiting the 'final user'. A researcher of smart-grid innovations pointed out that the financial benefits of active energy management are mostly for major commercial energy users, such as large retail chains that can shift the time when they use their refrigerators, for example. There is a similar benefit for large companies, for whom relevant arrangements in getting compensated for their flexibility in energy use predate the smart grids by several years. However, current smart-grid devices, smart meters in particular, have in fact shown relatively limited capabilities in changing energy consumption only at that layer of the energy infrastructure. This has been evidenced in countries such as Finland and Sweden that have rolled out smart meters. There, patterns of electricity consumption have remained stable and predictable with little evidence of the anticipated new forms of consumer response. This corresponds with a pertinent finding by sociological studies. Namely, consumers engage with new smart technologies in diverse and often unpredictable ways, with their consumption deeply ingrained in everyday habits most of the time; thus the experts' faith in 'rational individuals' conveys an idealization [22,27,65-67]. That being said, adding 'smartness' to power grids is not merely about new forms of consumption for it could also bring about new smarter energy services for these energy users.

Energy suppliers and distribution operators can access a considerable amount of new data from smart meters and apply that to various ends. As our informants envisaged, these include improvements to supply-demand balancing, infrastructure reinforcements, network optimization, planning, and identification of power outages. In the related sector of smart water meters, infrastructure managers anticipate significant benefits arising from more detailed knowledge about water use, improvements in efficiency via reduced consumption, reduced costs, and capturing the variation of water use during 
the week and days as part of infrastructure planning [73]. However, infrastructure suppliers could also use the increased 'smartness' to offer new added-value services to their customers. One relatively simple and common example is time of use tariffs of electricity that vary according to the hour; this is still consistent with the visions of more rational consumers whose interest is in saving money. More complex demand-side flexibility services might put buffers between energy production and energy use by creating services that automate the switching of tariffs or even steer household appliances in ways largely invisible to the consumers. These expectations of users of smart energy services, rather than just users of smart meters, also have very particular implications for the design of smart-grid infrastructure, as we show below.

In addition to conventional energy suppliers and distribution operators, there could be an opportunity for a host of service providers to use the smart grid to enter the energy supply markets. Developers of ICT systems, or so-called next-generation intermediaries, have already emerged in Finland with its full digital automatic meter-reading across the country (Figure 1). There, a number of new automation and analysis programmes now offer to draw on the data from the smart meters and translate it for the use of consumers in a variety of ways [69]. These include the formation of 'virtual power plants' that reduce demand by pooling stocks of households (typically some hundreds or thousands) among whom (invisible) load shifting in use of electric heating and electric appliances can be achieved.

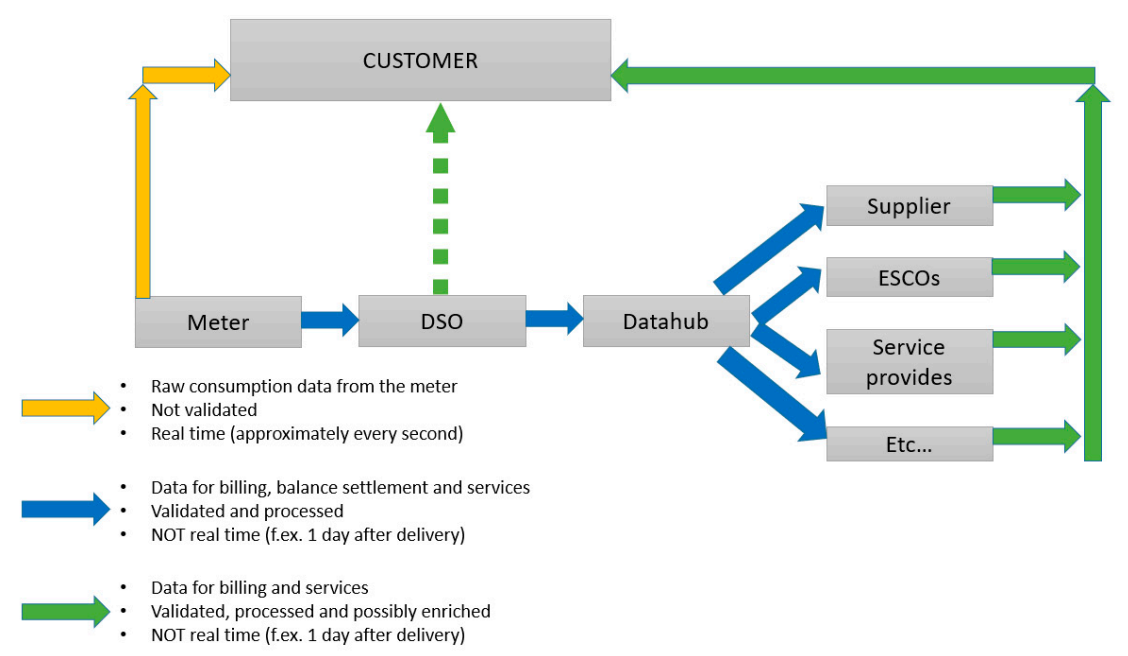

Figure 1. Potential new energy services via next-generation electricity meters in Finland. Source: [74].

\subsection{Differing Time Spans of Benefits: Users of Current Smart Grid Configurations or Users of Future Intelligent Networks?}

The difference between present-day users of smart meters and users of emerging energy services leads to a point on different temporalities of benefits of 'smartness'. It would seem that concerns over how users could save money are mainly represented as important in the early stages of smart meter rollout. As the smart grid infrastructure evolves, however, new differences could emerge between the users of the current smart grids and the more flexible users of future intelligent energy networks.

Rather than merely seeing them as optimizing their energy use, the representation of smart grid users was tangled up with broader infrastructural visions, technological developments, and associated issues. The informants anticipated that peak consumer demands in electricity will become an increasing problem. For example, with the adoption of electric vehicles, the population of drivers arriving home at the same time may strain the electricity grid. Similar problems, but on the generation side, were seen to arise from the transition to renewable energy sources (e.g., wind and solar) where output is intermittent depending on weather and season and often difficult to foresee, creating issues for supply-demand balancing as well as for maintaining stable electricity grids. Altogether, a whole 
chain of policy problems and visions could shape the importance of smart grids for society over the coming decades. The head of an energy institute in mainland Europe explained this policy dynamic:

We should ask though why decarbonization is so important. Decarbonization is following the top priority of addressing climate change. Here we have an important driver for decarbonization itself. The other key issues in the decarbonization target of the European Commission and at world level include the environmental aspect of pollution, so several new countries are deciding one after the other a switch off date for gasoline cars. The main driver here is not climate change but environmental issues, in order to prevent the consequences of having polluted cities.

These policy priorities put particular strain on the infrastructure of the electricity grid to withstand unpredictability in supply and demand. The informants thought that smartness offers a key pathway for minimizing the risk of outages and inadequate service. Smart grids thus are not merely meters added with ICTs, but as one researcher working in Austria put it, they "are intelligent grids that are made to be stable - the aspiration of electrical engineering is avoidance of faults and of excessive production or consumption." The users of these future intelligent networks will obviously be very different from the users of current smart grid configurations, particularly those restricted to just having smart meters. Evidently, a number of new roles are available for the future smart grid 'users' across the energy supply chain (Figure 2).

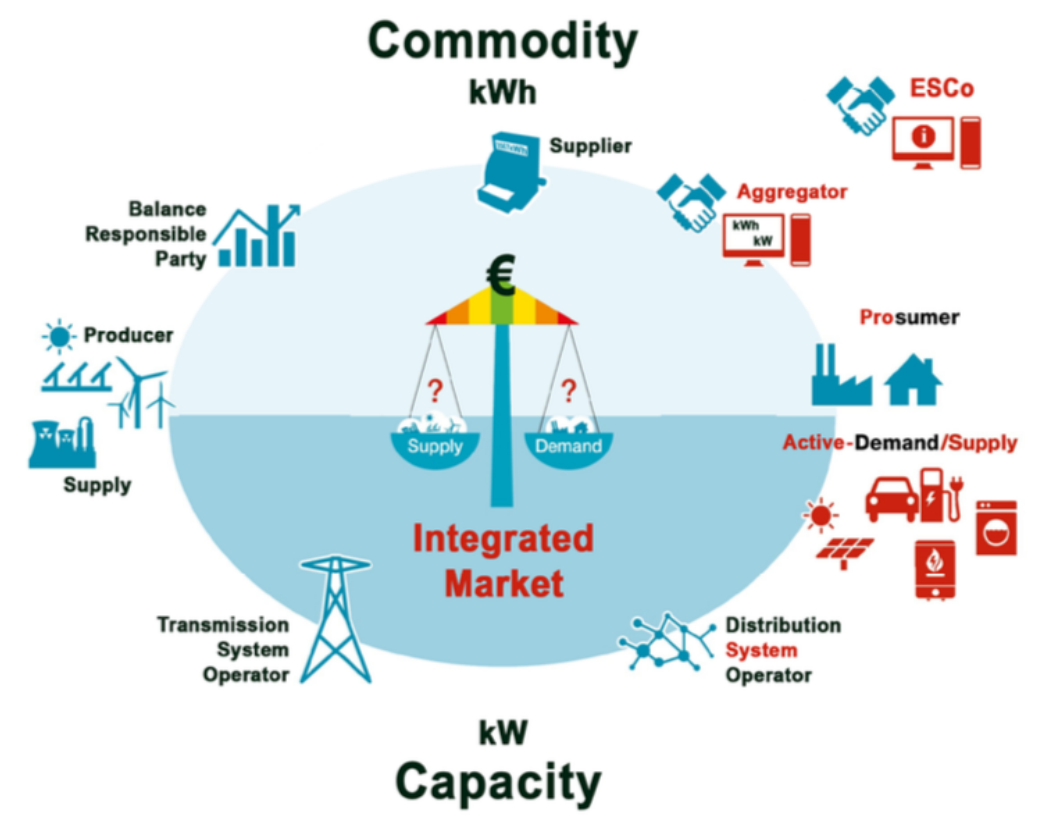

Figure 2. New and existing roles in smart energy frameworks. Source: [75].

4.3. Differing Perceptions of What is a Smart Grid: Everyone is in a Grid or Specific and Differentially Impacted Groups of Users?

At this point, there is a blurring in the smart grid concept between suppliers and customers, as indeed, potentially everyone is a 'user' of 'smartness' in the future's more intelligent energy networks. In these scenarios, smart energy services are not necessarily meant for just affluent populations, for example those owning electric vehicles, ground heat pumps, or 'smart' homes [63]. Smart grids can, but do not necessarily have to, follow upon the earlier logics of liberalization, where energy markets were segmented so that those willing to pay can be offered higher-quality infrastructure services [76]. Smart grid infrastructures do not inevitably lead either to reinforcing differences or to equalization. Indeed, our respondents had no single view on these issues. To some respondents, it seems, variations of service were inherent in all liberalized provisions. Other informants recognized the potential 'sorting' of customers 
as an issue and reflected on it extensively, suggesting new forms of knowledge and interventions that could help to understand specific and differentially impacted groups of users.

While our respondents often spoke about different industrial 'users' of smart energy, in the majority of cases, when our informants mentioned the 'user', they actually meant final users such as households, individuals, or in some cases, energy-using communities. Many of our experts also wanted to pursue specific work to identify their needs and build a 'bridge' toward achieving them. Their concept of the 'user' clearly changed in explaining this issue: away from the abstract diagrammatic idea of the user in the two-way web of smart energy systems, to associating users very closely with 'real' flesh-and-blood people, drawing upon their socio-demographic and attitudinal characteristics such as type of household, age, region, income, consumer interest, trust and risk perception, and even their vulnerability. An economist who had run public workshops on this topic in the UK summed up:

I think a factor might be consumers' interest towards reducing their bills, however it was when we did public workshops for example on that, people don't see the trade off in terms of higher electricity bills versus flexibility that they need to create.

Another recent focus group on smart meters discovered that consumers are positively predisposed to demand-side management and smart technologies in general, but, at least without first-hand experience from smart energy services, reluctant to accept automated systems if they are controlled by energy suppliers [77]. Not only could such socio-economic variables explain smart metering use and acceptance, but also the protests against them. At least according to one informant, such protests are shaped by "the feeling in the local community" concerning infrastructure projects rather than opposition to the dangers of technology as such.

There have been long-term attempts within industries to comprehend the needs of energy consumers: energy supply companies engage in market research that aims to segment customers, and to identify their interest in different products and their preference for billing models that are also linked with their acceptance of 'smartness'. Indeed, in temporal terms, many of our subjects suggested that such conventional knowledge still shapes smart energy innovations: Namely, users are brought into the smart energy development at a late stage, where they can tweak functionalities but not thoroughly change designs [27]. This tendency can be reinforced by the fragmentation of roles and responsibilities in liberalized energy supply and distribution [54]. Thus, meter manufacturers have little direct contact with end users. As a representative of meter manufacturers told us:

Making smart energy meters often has little direct relation to energy end users in their homes. First, the manufacturers do not sell smart meters directly to the public. The end users, for their part, will be very rarely looking directly at their energy meter even if it is a 'smart' meter. The meter may be placed under the stairs or other difficult locations to see. There are other companies making In-Home Displays (IHDs) and apps on the phone for these smart meters. They do engage in market research. There have been a few companies that both manufactured meters and the IHD for it but in the UK's next Smart Metering Equipment Technical Specification (SMETS) 2.0, no companies are present that do both.

The 'active and rational consumer' is at once at the centre of many smart grid programmes; yet, as this quote suggests, the research on smart energy services is only done by select organizations. How much do we know about these 'active users' and what other metaphors might inform smart development projects?

\subsection{Varying Certainty of User and Technology Representations in Different Parts of Smart Grids}

The anticipated 'users' of smart technologies fall within a wide range, including many intermediaries between 'producers' and 'users'. In this fashion, the umbrella term 'user' masks a range of emerging interests, from households to microbusinesses, new energy service providers, consumption aggregators, price comparison web sites, and even the energy systems operators themselves. However, the kinds of 
'user' that benefitted most directly, according to our informants, were professionals including electricity suppliers and network operators, meter manufacturers, ICT companies, and other intermediaries. Benefits to consumers for 'self-managing' energy were anticipated, but also sometimes markedly difficult to evidence with certainty.

According to our respondents, this matter could be resolved by long-term research that seeks to understand better the end-users and uses of energy more generally. Our research informants suggested that the possibilities that people will see in smart energy technologies are shaped by the types of housing stock in different regions, the access to infrastructure (especially Internet connections, although interestingly not required by smart meters in the UK), lifestyle-based choices, household economics, and even the very fact that it is not just individuals, but often every person in a household who affects energy choices. One technical researcher thought that more knowledge of energy consumption in the household could even expose new conflicts in the family. In a recent study, anthropologists showed similarly how new home displays of smart meters in Norway and the UK brought complex social dynamics into being, "regarded as an ally by those members most concerned with saving on household electricity consumption by providing objective evidence of costs linked to specific practices" [67] (p. 13).

Vulnerable customers who have difficulty in paying their energy bills pose further questions to the smart energy infrastructure along these lines. Low-income people, especially those experiencing fuel poverty, have much to gain by reducing their bills, but our informants recognized that they will need very specific support to make use of the smart-meter information. As a researcher of smart-energy innovation pointed out, low-income people "often struggle with so many other problems that this is not their main priority." Building a bridge between preconceptions about 'users' and actual situations of use requires dedicated work in cases like this. Many ways to iterate between technologists and 'users' were suggested in our materials: for example, sending field agents to low-income families to discuss their budget management or creating special 'energy offices' that translate the ideal of money saving into the contexts of management of energy consumption at home.

With examples such as this, the aspiration of understanding the 'user' has taken almost a full turn from the infrastructural visions and promises that started our analysis. It seems that while smart projects envisage diverse 'users' of smart grid to be anyone at all, they also tend to discover their very variability and how well technology designers have understood the different conditions of use. Yet, even when developers address these issues, they are still 'representing' the user in a certain way that remains open to further discussion. For example, we would claim that even in this case, the developers and experts assumed the ideal of active, rational consumers; that is why they believed that financial counseling of residential consumers will help address problems with fuel poverty. Smart grid developers could pay explicit attention to recognizing these kinds of descriptions of the 'user', their underpinning assumptions, and also ask whether they correspond with the kinds of energy services that the smart grid can offer in the future, as we discuss next.

\subsection{Metaphors of System Evolution: Active, Rational Consumer or Routinized User of Optimization Services?}

For a number of years, social scientists have argued that the 'rational consumer' or 'resource man' envisaged by many smart development programmes conveys an idealized image [23,67]. We now know that relatively few people may have the interest or the capacity to analyze their energy meter readings all the time or very frequently in their everyday lives. We also know that householders experience infrastructures as part of their everyday life, relating to various social practices, ingrained habits, household technologies, and socio-cultural contexts of daily life $[78,79]$. Considering these contexts, persuading users to become more active participants in 'smartness' tends to be time-consuming, and some informants found appeal in innovations that partially sidestep these issues and automate energy use: for example, by letting an autonomous agent switch residential energy tariffs.

A developer of such automation said that it is an essential element in smartness, notwithstanding the few exceptional individuals who are willing to give constant attention to their energy usage. "I think you have to have automation where you have that sort of variability.... With the increased 
complexity of variable use, variable tariffs, you have to have the corresponding automation." As this example shows, automation offers a more plausible way for users to control electricity use. Rather than imagining a domestic consumer who checks prices all the time, it could provide a space for consumers to deliberate about the kinds of price/service trade-off they would like, for example delaying their use of household devices, or consenting to an energy tariff switch that was, as such, decided by autonomous software. Stepping away from the restricted focus on micro-decisions may also allow more space for providing information on other aspects that interest people in energy issues: such as the source of electricity or volumes of energy trade across national borders. Automation then does not simply mean that the end users become disinterested in energy. Indeed, studies have shown that some smart grids 'users', especially innovative 'lead user-consumers', have considerable capability to stimulate industry-wide innovation and articulate the social and societal responsibility relevant to energy markets [27].

In any case, whether designers focus on active and rational consumers or try to support routinized users of optimization services has important repercussions for the evolution of energy systems. Many of the current ambitions, such as more or less real-time measurements of energy consumption, are not possible with today's smart energy meters that measure energy by a 15-min or 30-min interval. If the ambitions are to be reached, then, this means future systems should be designed in a way that allows for information to be gathered in much finer detail than before: for example, via new devices called submeters, which allow for nearly real-time readings. This would enable suppliers to gather data about consumers, but also involve consumers to generate more nuanced demand-side responses to the signals that they receive from their meter. As a technologist explained, however, enabling consumers' demand-side responses does not only need "fast and reactive" real-time measurements, but also energy providers gaining access to the final appliances at home so that they can partly control them. Such solutions have been tested but are not available on the mass markets. These considerations show that an emphasis on the directly active and rational consumer has to be paired with one equipped with smart systems that measure and control energy use down to the detail of final appliances, potentially requiring relatively sporadic active engagement.

This development could, however, open up privacy and data protection issues. In the example of the Netherlands, lawyers deemed that smart meter readings more frequent than every 15 min infringe the European Convention on Human Rights [70]. Additionally, the access of network operators, suppliers, and third parties to smart metering data triggered public opposition there [17]. A researcher of smart systems in the UK agreed on such concerns by noting that "there is a lot of personal information that one can get from a smart meter so they're absolutely right to be worried about the privacy of it." As another researcher of smart technologies noted, protests belong to democratic contestation and can bring these kinds of issue to the fore: their key value is "getting something into the agenda or calling attention to something."

In contrast, an emphasis on the routinized users of optimization services has different implications for the evolution of the energy system. This focus includes consideration of energy sources-especially intermittent renewable energy-but also the electricity distribution system where the 'smartness' is envisaged to provide major changes. In this case, smart grids and smart meters will themselves act as infrastructures for demand response and optimization services in the future. This means that, for operators, service providers, 'third party intermediaries', utilities, and developers, the focus should be on the interoperation of smart grids and other infrastructures and linking the abundance of new data from smart meters to advances in the expanding systems by ICT developers, who our respondents saw as significant drivers of smart energy developments.

Altogether, the expert considerations in country contexts that do not as yet have two-way metering systems in place resemble the past discourse in settings such as Finland where remote real-time control of both heat and electricity is already possible. Experts in these countries-indicated at least in Finland as well as Norway-see the future quite differently by now. The major thrust appears to be that home energy consumption is and will remain highly routinized and that smart automation systems will not 
primarily operate by way of decision systems that offer price signals and expect people to respond. Such information guidance is likely to feature as one part of the service. However, we could think of examples where it will remain reserved for informing consumers about the rare extremely high peak energy prices (tens or hundreds of times the average). Otherwise, they will proceed by two to five preset programs by which the energy consumption of the household is organized (such as 'no constraints', 'week day pattern', 'max load shifting', 'away'), between which consumers switch via control panels and cellphone apps [69].

\subsection{Cui Bono? What Can Early Assessment Assert About the Harms and Benefits of Smart Grid Projects?}

In current debates concerning the spread of smart meters across societies, a key concern by social scientists has linked with questions posed by the sociology of user representations and the sociology of expectations. These issues are related to the manner in which the 'user' is envisaged in smart development projects and to the kind of industry-wide expectations of 'uses' that give shape to these representations. Recently, one main concern in this respect has been that smart metering should be 'socially' integrated into everyday life, to avoid causing potential resistance when it is not 'socially' integrated enough and leading to a need to inquire more closely into how users and use are conceived [80]. As a way of counter-argument, public campaigns on smart meters have drawn upon independent surveys [81] to measure consumer acceptance: for example, to indicate almost all the population, such as in the UK, are aware of smart meters, the majority of whom would recommend smart meters to their peers, with many of them expecting to get a smart meter soon [82]. In these ways, the meters are 'socially' integrated into everyday life insofar as, according to surveys, they would be accepted by the population to accomplish that.

The two arguments are obviously different. However, they share one key assumption about evaluation: what happens is an early assessment of the harms and benefits of smart meters as they are being rolled out, whether this is done by social science analysis of policy programmes or large-scale consumer surveys. This premise is indeed very helpful especially for understanding the user-technology relationships in currently existing smart meters and smart grids. If smart grids and smart meters will rather become an infrastructure for a host of future intelligent optimization and other services, then it might not yet be fully known who will 'benefit' and who will 'lose' from them.

Whereas certain problems may recede into the background (for example, those predicated on creating rational, interactive consumers), others may intensify (such as concerns with privacy and human rights). Therefore, as in any other large-scale system and infrastructure, room should be preserved for the user representation to evolve along with technological advances and experiences from early assessments. Early in the European smart meter rollout, a report to the European Consumer Organisation BEUC argued that in order to avoid technological lock-ins, "beyond information to consumers, which is necessary but not sufficient, we suggest that consumers should be allowed to experiment different configurations of the smart meters while still in the process of invention." [83] (p. 2). This insight into learning and the co-evolution of technological innovations, users, and uses remains very relevant today.

Researchers and policy-makers pursuing smart grids might develop concepts and analyses of how such user representations evolve alongside the smart grid infrastructure and its multiple potential uses, and how these have played out in countries where smart grids are already further developed. In so doing, they might also keep a close eye on how that affects the risks that opponents of smart grids and meters claim to be inherent in these technologies.

\section{Discussion}

By studying smart grid development projects and drawing upon insights from the social science and humanities as well as the experience of experts working in these fields and ICTs, we can now bring forward a number of views that take these issues further. 
This article focused on how smart grid development projects represent the 'user' of smart-grid and smart-metering technologies. We showed that there are varieties of 'user' of smart grids in such projects, only some of them conventional 'final users' such as households. Energy suppliers, electricity distribution operators, automation analysis software providers, price comparison websites, smart homes, and others are linked to the smart grid promises, themselves shaped by wider visions about decarbonization and cost minimization. Yet, in the majority of cases, the experts involved in the CANDID research still envisaged the user-often a household—as actually the 'final user', or as a person in the fuller sociological meaning. In different ways, this user was expected to become more active than the current largely routinized energy consumers are [78] and motivated to save money and energy by using smart technologies, or even becoming a more active participant in energy provision altogether.

At this point, smart systems encounter a difficulty about which social scientists know much, including those in our study and many energy experts in industries and governments. The problem corresponds to the 'users' and uses of most large-scale infrastructures, as exemplified by the Internet [44]. In a system that envisages connecting anyone who uses energy-in practice, millions of consumers-it is very hard to know what each 'user' needs and to tailor the offered system to these [7]. With these issues in view, energy industries and manufacturers have needed to 'produce' different 'supposed' users, thus helping them to design, produce, and market their products. In contrast to what is sometimes assumed, these analysts are not merely suggesting that all these 'supposed' users be replaced with input from 'actual users' or 'real users'. As Hyysalo and Johnson [35] argue, such a move could restrict choices in the human-centered design of technology. This article developed a theoretical perspective for opening up user-technology relations further and applied it to study the developers of smart-grid infrastructures.

Working from these perspectives, we observed a number of the features identified in earlier work on the sociology of user representations to be at play with smart-grid development as well. These include discovering a range of competing user representations in an emerging technology; observing that developers reduce the complexity of these representations through simplifying user characteristics; and noting that user representations are not mere abstract exercises but play important roles in the expectation work of mobilizing resources and support as well as for developing emerging technologies such as smart grids and smart meters.

Beyond this, smart-grid user representations draw attention to a set of new issues in how users are represented in emerging and multi-layered infrastructures:

1. The likely intensity of users' engagement with smart-grid technologies varies considerably: at the one end of the spectrum, users draw on smart technologies to carry out limited optimization of their energy usage; at the other end are 'prosumers' who actively optimize their own production, storage, and home energy use and transit electricity themselves.

2. There is a significant temporal difference: the represented user could be expected to engage with currently existing smart-metering solutions, or with intelligent optimization software and services that are envisaged to be in place once the smart grid is mature sometime in the 2020s.

3. These differences find their corollary in whether the user is seen just in terms of the smart meter (and perhaps supplemented by visualization tools), or more comprehensively through the adoption of further layers of services and applications.

Many of these representations would entail a dramatic increase in the presumed rationality of users. Others are compatible with the concept of the routine consumer who chooses a contractual regime that determines how much optimization and demand-response takes place and how often $\mathrm{s} /$ he can switch between preset options. This latter representation also includes consumers who are motivated in part by saving money—-they are just doing it in very different terms from the envisaged active users. However, we add an important caveat to these findings. These 'preconfigurations' of 'the user' capture important aspects of active decision-making and habits as part of the user-technology 
relationship. They might be less sensitive to the experiences of those users and public that become resistant to the capacities of the enrolled technologies. Examining these issues further may require a shift in terminology, from 'user' or 'consumer' to 'citizen', 'right holder', or 'public', in future studies.

All of the above has significant implications for understanding how adequate our conceptualizations of the smart grid user are, and also how well we are able to assess the eventual impacts of these technologies. If one asserts that the smart grid consists primarily of added remote metering, the root image would veer towards the active and rational consumer who is busy optimizing energy usage and planning. On the other hand, if one projects that smart meters are only the infrastructural basis for arrays of optimization and demand-response services to come and are likely to feature considerable contract and service variety, the images of represented users change. The range of users grows much wider and use becomes potentially more voluntary, subject to service contracts purchased from new markets. The eventual impacts on people are likely to evolve, reflecting pertinent regulatory and technological decisions made over time. Importantly, this provides room to learn from the manifested impacts so that adverse effects can be remedied, with the strong points of smart-grid technologies being capitalized on both in regulatory regimes and in digitalized service development.

\section{Conclusions}

Understanding what the different representations of 'users' are-and where the boundaries of these supposed uses lie-provides important input for designing smart energy systems and discussing how 'responsible' these innovations are likely to become for different users and toward other societal actors. Concerns over the inadequacy of merely introducing remote sensing and two-way provision technical capacities to the existing networks need to be taken seriously. On the basis of analyzing user representations of smart grids, we have argued that such limited functioning of smart grid infrastructures is not likely to be the end-state of their evolution and appears not to be the desired state. This situation calls for a systematic exploration of optimization and demand-response systems that would bring wider and different arrays of benefits to different consumer segments.

To steer the development of smart grid infrastructures and associated evolving user representations, infrastructural evolution should also be periodically monitored from the point of view of the various consumers. Such anticipatory assessment might usefully include monitoring for developments that veer towards partisan or unduly narrow models of infrastructural operation, service provision or ownership, and give balanced attention to disbenefits and harms as well as benefits sought earlier on. Policy-makers, innovators, and researchers pursuing smartness could explore evidence from the varying experimental development strategies in different contexts and countries that, for example, seek to grow systems incrementally by solving current demands and attending to future needs. Such long-term periodic assessment and steering strategy has been practiced within constructive technology assessment [84] and in the management of radical innovations [85]. If coupled with systematic consultations in different country settings, they could fit particularly well with the governance of smart grids that is being developed in somewhat different configurations in many settings for a foreseeably long time.

By deploying the strategic approach developed in this article, smart grid developers and experts could give more explicit attention to recognizing the descriptions of 'users' in smart grid projects. They could ask what level of engagement is expected of these 'users', and how feasible these expectations of 'use' are in comparison to the possibilities and limits of existing, or future, energy services and applications. Conversely, examination of user representations can highlight the need for further technology and service development if some of the envisioned user profiles and user actions appear unrealistic for presently available technologies. Smart-grid user representations clearly indicate the need to move beyond smart meters and focus development efforts for further layers of services available for differently oriented consumers. These descriptions of the 'user' should not be assessed just once, but periodically updated as development projects evolve and the related smart technologies mature. Cross-country comparisons, which we have started to conduct in this article, would provide critical input to these assessments, helping to discover previously overlooked representations of 'users' by drawing 
on contexts where the smart grid is configured very differently. Much research and development work remains to be done in understanding the emerging usage, services, regulatory choices, and implications of smart-energy technologies from these perspectives.

Author Contributions: Conceptualization, S.H., R.W., A.S., and K.R.; methodology, A.S., K.R., S.H., and R.W.; investigation, A.S. and S.H.; writing-original draft preparation, A.S., and S.H.; writing-review and editing, R.W., C.R., and K.R.; project coordination, K.R.; funding acquisition, K.R., R.W., C.R., and A.S.

Funding: This research was funded by the "Checking Assumptions and Promoting Responsibility in Smart Development Projects" (CANDID) EU research programme. European Commission Horizon 2020 (2017, grant number 732561, www.candid.no). Kjetil Rommetveit also wishes to recognize the funding provided by the Norwegian Research Council for the ERA-Net project PARENT, project number 259777. Sampsa Hyysalo acknowledges funding from Strategic Research Council of Finland grant number 133143251, "Smart Energy Transition".

Acknowledgments: We acknowledge with thanks the helpful comments received from Andres Dominguez, Andrey M. Elizondo Solano, Alessia Tanas, Niels van Dijk, and Maxigas Dunajcsik.

Conflicts of Interest: The authors declare no conflict of interest.

\section{Appendix}

\section{The Structure of the Consultation Questions}

1. Who do you see as the most important potential kinds of user of smart grids and smart meters? Please provide a list.

2. For each of these users, can you detail how you think they might use these technologies and what would be their main benefits and limitations?

3. Do specific kinds of users have difficulties to access the potential benefits of smart grids and smart meter technology? Why?

4. Do you think that some users are reluctant to adopt smart grids and smart meter technologies despite having access and being aware of their potential benefits? Please, give us some real case examples if possible.

5. Does the notion of 'smart' have different nuances between different kinds of users: for example, 'savvy' users such as citizen initiatives or the quantified-self movement, or consumer groups advocating more consumer-led smart energy developments? Do these conceptions differ from or resemble those of smart device manufacturers or energy companies?

6. Which needs are driving smart energy developments: for example, 'technological push' from the ICT industry, the electric power generators and distributors, or the needs of energy users?

7. Are users usually involved and do they participate in designing these technologies? How?

8. What advantages and disadvantages may user involvement bring for designing smart energy technologies?

9. 'Smartness' raises crucial questions about the protection of fundamental rights and values like privacy, data protection, and autonomy. Anti-smart meter campaigns, lawsuits against smart metering, consumer organization critiques, and motions against smart meters exemplify these problems. Do you think these objections have made designers and policy-makers reconsider and modify their projects? Please provide details of any examples where you think this has happened.

10. How do expectations about the users and uses of smart energy technology differ across countries, for example in different EU member states?

\section{References}

1. Executive Office of the President of the United States. A Policy Framework for the 21st Century Grid: Enabling Our Secure Energy Future. Available online: https://obamawhitehouse.archives.gov/sites/ default/files/microsites/ostp/nstc-smart-grid-june2011.pdf (accessed on 28 August 2018).

2. European Parliament and Council. Directive on energy efficiency, amending Directives 2009/125/EC and 2010/30/EU and repealing Directives 2004/8/EC and 2006/32/EC. 2012/27/EU. 2012. Off. J. Eur. Union $2012,315,1-49$. 
3. UK National Infrastructure Commission. Smart Power. Available online: https:/ / assets.publishing.service. gov.uk/government/uploads/system/uploads/attachment_data/file/505218/IC_Energy_Report_web.pdf (accessed on 28 August 2018).

4. $\quad$ Frickel, S.; Wühr, D.; Horne, C.; Kallman, M.E. Field of Visions: Interorganizational Challenges to the Smart Energy Transition in Washington State. Brooklyn Law Rev. 2017, 82, 693-724.

5. UK Department of Business, Energy \& Industrial Strategy. Smart Meter Rollout Cost-Benefit Analysis Part I. Available online: https://assets.publishing.service.gov.uk/government/uploads/system/uploads/attachment_ data/file/567167/OFFSEN_2016_smart_meters_cost-benefit-update_Part_I_FINAL_VERSION.PDF (accessed on 28 August 2018).

6. Institute of Communication \& Computer Systems of the National Technical, University of Athens; AF-MERCADOS EMI. Study on cost benefit analysis of Smart Metering Systems in EU Member States, final report. Available online: https:/ / ec.europa.eu/energy/sites/ener/files/documents / AF\%20Mercados\% 20NTUA\%20CBA\%20Final\%20Report\%20June\%2015.pdf (accessed on 28 August 2018).

7. Rommetveit, K.; Dunajcsik, M.; Tanas, A.; Silvast, A.; Gunnarsdóttir, K. The CANDID Primer: Including Social Sciences and Humanities scholarship in the making and use of smart ICT technologies. CANDID (H2020-ICT-35-2016). Available online: http:/ / candid.no/progress (accessed on 28 August 2018).

8. van Dijk, N.; Tanas, A.; Rommetveit, K.; Raab, C. Right engineering? The Redesign of Privacy and Personal Data Protection. Int. Rev. Law Comput. Technol. 2018, 32, 1-27. [CrossRef]

9. European Commission. Smart grid. From Innovation to Deployment. Available online: https:/ / eur-lex. europa.eu/LexUriServ/LexUriServ.do?uri=COM:2011:0202:FIN:EN:PDF (accessed on 28 August 2018 ).

10. European Commission. Benchmarking smart metering deployment in the EU-27 with a focus on electricity. Available online: https:/ / eur-lex.europa.eu/legal-content/EN/TXT/?uri=COM\%3A2014\%3A356\%3AFIN (accessed on 28 August 2018).

11. UK Department of Energy and Climate Change. Smart Metering Implementation Programme. Available online: https://assets.publishing.service.gov.uk/government/uploads/system/uploads/attachment_data/ file/68976/Smart_metering_programme_update_-_April_2012.pdf (accessed on 28 August 2018).

12. UK House of Commons. Evidence Check: Smart metering of electricity and gas. Science and Technology Committee. Available online: https:/ / publications.parliament.uk/pa/cm201617/cmselect/cmsctech/161/ 161.pdf (accessed on 28 August 2018).

13. Helm, D. Cost of Energy Review: Independent report for the UK Government. Available online: https: / /www.gov.uk/government/publications/cost-of-energy-independent-review (accessed on 28 August 2018).

14. Hess, D.J.; Coley, J.S. Wireless smart meters and public acceptance: The environment, limited choices, and precautionary politics. Public Understan. Sci. 2014, 23, 688-702. [CrossRef] [PubMed]

15. van der Horst, D.; Staddon, S.; Webb, J. Smart Energy, and Society? Technol. Anal. Strateg. Manag. 2014, 26, 1111-1117. [CrossRef]

16. von Schomberg, R. Towards Responsible Research and Innovation in the Information and Communication Technologies and Security Technologies Fields. In Towards Responsible Research and Innovation in the Information and Communication Technologies and Security Technologies Fields; von Schomberg, R., Ed.; European Commission Services: Brussels, Belgium, 2011; pp. 7-16.

17. Hoenkamp, R.; Huitema, G.B.; de Moor-van Vugt, A.J. The neglected consumer: The case of the smart meter rollout in the Netherlands. Renew. Energy Law Policy Rev. 2011, 4, 269-282. [CrossRef]

18. Oudshoorn, N.; Pinch, T. How Users Matter: The Co-construction of Users and Technology; MIT Press: Cambridge, MA, USA, 2003.

19. Hyysalo, S.; Jensen, T.E.; Oudshoorn, N. The New Production of Users: Changing Innovation Collectives and Involvement Strategies; Routledge: London, UK, 2016.

20. Wolsink, M. The Research Agenda on Social Acceptance of Distributed Generation in Smart Grid: Renewable as Common Pool Resources. Renew. Sustain. Energy Rev. 2012, 16, 822-835. [CrossRef]

21. Darby, S.J. Metering: EU Policy and Implications for Fuel Poor Households. Energy Policy 2012, 49, 98-106. [CrossRef]

22. Nyborg, S.; Røpke, I. Constructing Users in the Smart Grid - Insights from the Danish eFlex Project. Energy Effic. 2013, 6, 655-670. [CrossRef]

23. Strengers, Y. Smart Energy Technologies in Everyday Life: Smart Utopia? Springer: Berlin, Germany, 2013. 
24. Skjølsvold, T.M.; Ryghaug, M.; Berker, T. A Traveler's Guide to Smart Grid and the Social Sciences. Energy Res Soc. Sci. 2015, 9, 1-8. [CrossRef]

25. Ballo, I.F. Imagining Energy Futures: Sociotechnical Imaginaries of the Future Smart Grid in Norway. Energy Res. Soc. Sci. 2015, 9, 9-20. [CrossRef]

26. Bulkeley, H.; Powells, G.; Bell, S. Smart Grid and the Constitution of Solar Electricity Conduct. Environ. Plann. A 2016, 48, 7-23. [CrossRef]

27. Heiskanen, E.; Matschoss, K. Consumers as innovators in the electricity sector? Consumer perceptions on smart grid services. Int. J. Consum. Stud. 2016, 40, 665-674. [CrossRef]

28. Throndsen, W. What Do Experts Talk about When They talk about Users? Expectations and Imagined Users in the Smart Grid. Energy Effic. 2017, 10, 283-297. [CrossRef]

29. Lovell, H.; Pullinger, M.; Webb, J. How do Meters Mediate? Energy Meters, Boundary Objects and Household Transitions in Australia and the United Kingdom. Energy Res. Soc. Sci. 2017, 34, 252-259. [CrossRef]

30. Sumpf, P.; Klemm, M.; Throndsen, W.; Büscher, C.; Robison, R.; Schippl, J.; Foulds, C.; Buchmann, K.; Nikolaev, A.; Kern-Gillard, T. Energy System Optimisation and Smart Technologies-A Social Sciences and Humanities Annotated Bibliography. Available online: https://shapeenergy.eu/wp-content/uploads/ 2017/07/SHAPE-ENERGY-Annotated-Bibliography_ENERGY-SYSTEM-OPTIMISATION-AND-SMARTTECHNOLOGIES.pdf (accessed on 28 August 2018).

31. Bijker, W.; Hughes, T.P.; Pinch, T. The Social Construction of Technological Systems: New Directions in the Sociology and History of Technology; MIT Press: Cambridge, MA, USA, 1987.

32. Akrich, M. The De-Scription of Technical Objects. In Shaping Technology/Building Society: Studies in Sociotechnical Change; Bijker, W., Law, J., Eds.; MIT Press: Cambridge, MA, USA, 1992; pp. 205-224.

33. Oudshoorn, N.; Rommes, E.; Stienstra, M. Configuring the User as Everybody: Gender and Design Cultures in Information and Communication Technologies. Sci. Technol. Hum. Values 2004, 29, 30-63. [CrossRef]

34. Stewart, J.; Williams, R. The Wrong Trousers? Beyond the Design Fallacy: Social Learning and the User. In User Involvement in Innovation Processes: Strategies and Limitations from a Socio-Technical Perspective; Rohracher, H., Ed.; Profil-Verlag: Munich, Germany, 2005; pp. 195-221.

35. Hyysalo, S.; Johnson, M. The User as Relational Entity: Options that Deeper Insight into User Representations Opens for Human-Centered Design. Inf. Technol. People 2015, 28, 72-89. [CrossRef]

36. Akrich, M. User representations: Practices, methods and sociology. In Managing Technology in Society. The Approach of Constructive Technology Assessment; Rip, A., Misa, T.J., Schot, J., Eds.; Pinter Publisher: London, UK, 1995; pp. 167-184.

37. Hyysalo, S. Uses of Innovation. Wristcare in the Practices of Engineers and Elderly. Ph.D. Thesis, University of Helsinki, Helsinki, Finland, 2004.

38. Woolgar, S. Configuring the user: The case of usability trials. Soc. Rev. 1990, 38, 58-99. [CrossRef]

39. Williams, R.; Stewart, J.; Slack, R. Social Learning in Technological Innovation: Experimenting with Information and Communication Technologies; Edward Elgar Publishing: Cheltenham, UK, 2005.

40. Johnson, J.; Latour, B. Mixing humans and nonhumans together: The sociology of a door-closer. Soc. Probl. 1988, 35, 298-310. [CrossRef]

41. Madeleine, A.; Latour, B. A summary of a convenient vocabulary for the semiotics of human and nonhuman assemblies. In Shaping Technology/Building Society: Studies in Sociotechnical Change; Bijker, W.E., Law, D., Eds.; MIT Press: Cambridge, MA, USA, 1992; pp. 259-264.

42. Hyysalo, S. Health Technology Development and Use: From Practice-Bound Imagination to Evolving Impacts; Routledge: London, UK, 2010.

43. Johnson, M. How Social Media Changes User-Centered Design-Cumulative and Strategic User Involvement with Respect to Developer-User Social Distance. Ph.D. Thesis, University of Helsinki, Helsinki, Finland, 2013.

44. Edwards, P.N.; Jackson, S.J.; Bowker, G.; Knobel, C.B. Understanding infrastructure: Dynamics, tensions, and design. Report of a Workshop on "History \& Theory of Infrastructure: Lessons for New Scientific Cyberinfrastructures". Available online: https://deepblue.lib.umich.edu/bitstream/handle/2027.42/ 49353/UnderstandingInfrastructure2007.pdf? sequence=3\&isAllowed=y (accessed on 28 August 2018).

45. Pollock, N.; Williams, R. E-infrastructures: How do we know and understand them? Strategic ethnography and the biography of artefacts. Comput. Support. Cooperative Work 2010, 19, 521-556. [CrossRef] 
46. Pollock, N.; Williams, R.; D’Adderio, L. Generification as a Strategy: How Software Producers Configure Products, Manage User Communities and Segment Markets. In The New Production of Users: Changing Innovation Collectives and Involvement Strategies; Hyysalo, S., Jensen, T.E., Oudshoorn, N., Eds.; Routledge: London, UK, 2016; pp. 178-208.

47. Mozaffar, H. User Communities as Multi-Functional Spaces: Innovation, Collective Voice, Demand Articulation, Peer Informing and Professional Identity (and more). In The New Production of Users: Changing Innovation Collectives and Involvement Strategies; Hyysalo, S., Jensen, T.E., Oudshoorn, N., Eds.; Routledge: London, UK, 2016; pp. 219-248.

48. Stewart, J. The social consumption of information and communication technologies (ICTs): Insights from research on the appropriation and consumption of new ICTs in the domestic environment. Cognit. Technol. Work 2003, 5, 4-14. [CrossRef]

49. Konrad, K. Dynamics of type-based scenarios of use: Opening processes in early phases of interactive television and electronic marketplaces. Sci. Technol. Stud. 2008, 21, 3-26.

50. Wilkie, A.; Michael, M. Expectation and Mobilisation: Enacting Future Users. Sci. Technol. Hum. Values 2009, 34, 502-522. [CrossRef]

51. Stewart, J.; Hyysalo, S. Intermediaries, users and social learning in technological innovation. Int. J. Innov. Manag. 2008, 12, 295-325. [CrossRef]

52. Borup, M.; Brown, N.; Konrad, K.; van Lente, H. The sociology of expectations in science and technology. Technol. Anal. Strateg. Manag. 2006, 18, 285-298. [CrossRef]

53. Silvast, A. Energy, economics, and performativity: Reviewing theoretical advances in social studies of markets and energy. Energy Res. Soc. Sci. 2017, 34, 4-12. [CrossRef]

54. Silvast, A. Making Electricity Resilient: Risk and Security in a Liberalized Infrastructure; Routledge: London, UK, 2017.

55. Silvast, A. Co-constituting Supply and Demand: Managing Electricity in Two Neighbouring Control Rooms. In Infrastructures in Practice: The Evolution of Demand in Networked Societies; Shove, E., Trentmann, F., Eds.; Routledge: London, UK, 2018; pp. 171-183.

56. Verbong, G.; Beemsterboer, S.; Sengers, F. Smart Grid or Smart Users? Involving Users in Developing a Low Carbon Electricity Economy. Energy Policy 2013, 52, 117-125. [CrossRef]

57. Luque, A. The Smart Grid and the Interface between Energy, ICT and the City. In Urban Retrofitting for Sustainability: Mapping the Transition to 2050; Dixon, T., Eames, M., Hunt, M., Lannon, S., Eds.; Routledge: London, UK, 2014; pp. 159-173.

58. Powells, G.; Bulkeley, H.; McLean, A. Geographies of Smart Urban Power. In Smart Urbanism: Utopian Vision or False Dawn? Marvin, S., Luque-Ayala, A., McFarlane, C., Eds.; Routledge: London, UK, 2016; pp. 141-160.

59. Hargreaves, T.; Wilson, C. Who Uses Smart Home Technologies? Representations of Users by the Smart Home Industry. Available online: https:/ / www.eceee.org/library/conference_proceedings/eceee_Summer_Studies / 2013/6-appliances-product-policy-and-ict/who-uses-smart-home-technologies-representations-of-usersby-the-smart-home-industry/ (accessed on 28 August 2018).

60. Wilson, C.; Hargreaves, T.; Hauxwell-Baldwin, R. Smart Homes and their Users: A Systematic Analysis and Key Challenges. Pers. Ubiquitous Comput. 2015, 19, 463-476. [CrossRef]

61. Groves, C.; Henwood, K.; Shirani, F.; Butler, C.; Parkhill, K.; Pidgeon, N. Energy Biographies: Narrative Genres, Lifecourse Transitions, and Practice Change. Sci. Technol. Hum. Values 2016, 41, 483-508. [CrossRef]

62. Pullinger, M.; Lovell, H.; Webb, J. Influencing Household Energy Practices: A Critical Review of UK Smart Metering Standards and Commercial Feedback Devices. Technol. Anal. Strateg. Manag. 2014, 26, 1144-1162. [CrossRef]

63. Schick, L.; Gad, C. Flexible and Inflexible Energy Engagements-A Study of the Danish Smart Grid Strategy. Energy Res. Soc. Sci. 2015, 9, 51-59. [CrossRef]

64. Hansen, M.; Borup, M. Smart grids and households: How are household consumers represented in experimental projects? Technol. Anal. Strateg. Manag. 2018, 30, 255-267. [CrossRef]

65. Hargreaves, T.; Wilson, C. Domestication of Smart Home Technologies. In Smart Homes and Their Users; Hargreaves, T., Wilson, C., Eds.; Springer: Berlin, Germany, 2017; pp. 75-90.

66. Kahma, N.; Matschoss, K. The Rejection of Innovations? Rethinking Technology Diffusion and the Non-Use of Smart Energy Services in Finland. Energy Res. Soc. Sci. 2017, 34, 27-36. [CrossRef]

67. Winther, T.; Bell, S. Domesticating in home displays in selected British and Norwegian households. Sci. Technol. Stud. 2018, 31, 19-38. [CrossRef] 
68. Funtowicz, S.; Ravetz, J.R. Science for the Post-Normal Age. Futures 1993, 25, 735-755. [CrossRef]

69. Hyysalo, S.; Marttila, T.; Temmes, A.; Lovio, R.; Kivimaa, P.; Auvinen, K.; Pyhälammi, A.; Lukkarinen, A.; Peljo, J. Uusia Näkymiä Energiamurroksen Suomeen-Murrosareenan tuottamia kunnianhimoisia energia\& Ilmastotoimia Vuosille 2018-2030. Available online: http:/ / www.smartenergytransition.fi/tiedostot/ murrosareena-loppuraportti.pdf (accessed on 16 October 2018).

70. Cuijpers, C.; Koops, B.-J. Smart metering and privacy in Europe: Lessons from the Dutch case. In European Data Protection: Coming of Age; Gutwirth, S., Leenes, R., de Hert, P., Poullet, Y., Eds.; Springer: Berlin, Germany, 2013; pp. 269-293.

71. Hyysalo, S.; Pollock, N.; Williams, R. Method matters in the social study of technology: Investigating the biographies of artifacts and practices. Sci. Technol. Stud. 2018, prepublication.

72. Silvast, A.; Virtanen, M. Assemblages of Tamings and Framings: Multi-Sited Analysis of Infrastructures as a Methodology. J. Cult. Econ. 2018. under review.

73. March, H.; Morote, Á.F.; Rico, A.M.; Saurí, D. Household smart water metering in Spain: Insights from the experience of remote meter reading in Alicante. Sustainability 2017, 9, 582-600. [CrossRef]

74. Finnish Energy. Finnish Energy's position on the features of next-generation electricity meters. Finnish Energy. Available online: https:/ / energia.fi/files/1697/Finnish_Energy_position_paper_features_of_next_ generation_electricity_meters_final_20170810.pdf (accessed on 21 September 2018).

75. Smart Energy Collective. An Introduction to the Universal Smart Energy Framework. Smart Energy Collective. Available online: https:/ / ec.europa.eu/energy/sites/ener/files/documents/xpert_group3_ summary.pdf (accessed on 21 September 2018).

76. Graham, S.; Marvin, S. Splintering Urbanism: Networked Infrastructures, Technological Mobilities and the Urban Condition; Routledge: London, UK, 2001.

77. Mesarić, P.; Đukec, D.; Krajcar, S. Exploring the potential of energy consumers in smart grid using focus group methodology. Sustainability 2017, 9, 1463-1480. [CrossRef]

78. Shove, E.; Warde, A. Inconspicuous consumption: The sociology of consumption, lifestyles and the environment. In Sociological Theory and the Environment: Classical Foundations, Contemporary Insights; Dunlap, R.E., Buttel, F.H., Dickens, P., Gijswijt, A., Eds.; Rowman \& Littlefield Publishers: Lanham, ML, USA, 2001; pp. 230-251.

79. Shove, E.; Pantzar, M.; Watson, M. The Dynamics of Social Practice: Everyday Life and How it Changes; Sage Publishing: London, UK, 2012.

80. Sovacool, B.K.; Kivimaa, P.; Hielscher, S.; Jenkins, K. Vulnerability and resistance in the United Kingdom's smart meter transition. Energy Policy 2017, 109, 767-781. [CrossRef]

81. Smart Energy GB. Smart Energy Outlook. Available online: https: / /www.smartenergygb.org/en/resources/ press-centre/press-releases-folder/smart-energy-outlook-march18 (accessed on 28 August 2018).

82. Smart Energy GB hits back at smart meter research. Available online: https://www.electronicsweekly.com/ news/smart-energy-gb-hits-back-smart-meter-research-2017-09/ (accessed on 28 August 2018).

83. Klopfert, F.; Wallenborn, G. Empowering consumers through smart metering. Report for BEUC, the Bureau Europeen Des Unions Des Consommateurs. Available online: http:/ /www.beuc.eu/publications/201200369-01-e.pdf (accessed on 28 August 2018).

84. Rip, A.; Misa, T.J.; Schot, J. Managing Technology in Society. The Approach of Constructive Technology Assessment; Pinter Publisher: London, UK, 1995.

85. Raven, R.P.; Jolivet, E.; Mourik, R.M.; Feenstra, Y.C. ESTEEM: Managing societal acceptance in new energy projects: A toolbox method for project managers. Technol. Forecast. Soc. Chang. 2009, 76, 963-977. [CrossRef]

(C) 2018 by the authors. Licensee MDPI, Basel, Switzerland. This article is an open access article distributed under the terms and conditions of the Creative Commons Attribution (CC BY) license (http://creativecommons.org/licenses/by/4.0/). 